\title{
Cancer detection rates and inter-examiner variability of MRI/TRUS fusion targeted biopsy and systematic transrectal biopsy
}

\author{
Miroslav Zaleskya,b, Jiri Stejskal ${ }^{\mathrm{a}}$, Ivo Minarikc, Vanda Adamcovaa ${ }^{\mathrm{a}}$, Marek Babjukc, Roman Zachovala ${ }^{\mathrm{a}, \mathrm{b}}$
}

\begin{abstract}
Background. Software-based MRI/TRUS fusion biopsy depends on the coordination of several steps, and inter-examiner differences could influence the results. The aim of this bicentric prospective study was to compare the detection rates of MRI/TRUS fusion targeted biopsy (TG) and systematic biopsy (SB), and the detection rates of examiners with different levels of previous experience in prostate biopsy.

Methods. A total of 419 patients underwent MRI based on a suspicion of prostate cancer with elevated PSA levels. MRI was positive in 395 patients (221 in the first biopsy group [FB] and 174 in the repeated biopsy group [RB]). A subsequent TG, followed by a SB, was performed on these patients by four different examiners.

Results. In the detection of clinically significant prostate cancer, a significant difference was found for TG+SB against SB in the RB group ( $35.1 \%$ vs. $25.3 \%, P=0.047)$. In the detection of clinically insignificant prostate cancer, the $S B$ had a significantly higher detection rate than TG in both subgroups (FB: $11.9 \%$ vs. $4.7 \%, P=0.008$; RB: $13.8 \%$ vs. $6.9 \%, P=0.034$ ). A significant difference was found between the four examiners in the FB for TG $(P=0.028), \mathrm{SB}(P=0.036)$, and TG+SB $(P=0.017)$.

Conclusion. MRI/TRUS TG in combination with SB had significantly higher detection rates than SB in the RB group only. Differences in detection rates between examiners were dependent on the level of previous experience with TRUS guided biopsy.
\end{abstract}

Key words: biopsy, diagnostic imaging, fusion, magnetic resonance, prostate cancer

Received: March 26, 2019; Revised: September 21, 2019; Accepted: September 25, 2019; Available online: October 10, 2019 https://doi.org/10.5507/bp.2019.050

(c) 2020 The Authors; https://creativecommons.org/licenses/by/4.0/

${ }^{a}$ Department of Urology, Thomayer Hospital and 3rd Faculty of Medicine, Charles University, Prague, Czech Republic ${ }^{b}$ Department of Urology, $1^{\text {st }}$ Faculty of Medicine, Charles University, Prague, Czech Republic 'Department of Urology, $2^{\text {nd }}$ Faculty of Medicine, Charles University, University Hospital Motol, Prague, Czech Republic Corresponding author:Roman Zachoval, e-mail: roman.zachoval@ftn.cz

\section{INTRODUCTION}

The current diagnostic algorithm for prostate cancer detection based on PSA and subsequent systematic TRUS guided biopsy could be improved by adding mpMRI and targeted biopsy of MRI lesions ${ }^{1,2}$. MRI/TRUS fusion targeted biopsy is a multi-step procedure, the results of which depend on the quality of the mpMRI performance, $\mathrm{mpM}$ RI reading, and MRI/TRUS fusion and biopsy examiner performance. The inter-reader variability of mpMRI is a well-recognized factor influencing the results of examinations and subsequent MRI/TRUS fusion targeted biopsy ${ }^{3}$. Creation of the Prostate Imaging Reporting and Data System (PIRADS) was one way to improve this variability ${ }^{4}$.

Software-based MRI/TRUS fusion biopsy is dependent on the coordination of several procedural steps, and interexaminer differences could influence biopsy results. To the best of our knowledge, no studies have investigated the effect of examiner performance on the outcome of prostate fusion biopsy. The aim of this prospective study was to compare the detection rates of MRI/TRUS fusion targeted biopsies (TGs) and systematic biopsies (SBs), and the detection rates of different examiners performing these prostate biopsies.

\section{PATIENT AND METHODS}

\section{Study design}

This prospective study was approved by our local ethics committee. MRI was performed on 419 patients based on suspicion of prostate cancer with elevated PSA levels in period from 2015 to 2017. MRI was positive in 385 patients; 221 of the patients did not have a previous biopsy and 174 had a previous biopsy (mean 2.2 previous biopsies). All lesions were categorized into four groups according to PIRADS classification version 1 : negative $=$ PIRADS 1 or 2, PIRADS 3, PIRADS 4, and PIRADS 5. The study was designed in 2014 when PI-RADS v1 was routinely used. It was prospective therefore we used the PIRADS v1 classification in subsequent patient recruitments.

Subsequent MRI/TRUS fusion TG, followed by a SB was performed on these patients. TGs took 1-4 cores from MRI suspect lesions PIRADS $\geq 3$ (average 2.21 cores per lesion). Transrectal ultrasound and static type fusions were performed using a Toshiba Aplio 500 with fusion unit SmartFusion and a magnetic tracing device. Detection rates were calculated for all cancers, with subgroups of first biopsy (FB) and repeated biopsy (RB) for clinically significant and insignificant prostate cancers. 
Table 1. Age, PSA, and prostate size in the first and repeated biopsy groups.

\begin{tabular}{lcccc}
\hline & $\begin{array}{c}\text { Age, } \\
\text { years }\end{array}$ & PSA density & PSA, & \multicolumn{2}{c}{ Prostate size } \\
$\mathrm{mL} / \mathrm{mL}$
\end{tabular}

Table 2. Detection rates of clinically significant and insignificant prostate cancer stratified to the first and repeated biopsy groups.

\begin{tabular}{|c|c|c|c|}
\hline & $\begin{array}{c}\text { All } \\
\text { cancers }\end{array}$ & $\begin{array}{c}\text { Clinically significant } \\
\text { cancers }\end{array}$ & $\begin{array}{c}\text { Insignificant } \\
\text { cancers }\end{array}$ \\
\hline \multicolumn{4}{|l|}{ First biopsy group } \\
\hline MRI/TRUS targeted biopsy (TG) & $\begin{array}{c}74 \\
(35.07 \%)\end{array}$ & $\begin{array}{c}64 \\
(30.33 \%)\end{array}$ & $\begin{array}{c}10 \\
(4.74 \%)\end{array}$ \\
\hline Systematic biopsy (SB) & $\begin{array}{c}109 \\
(51.66 \%)\end{array}$ & $\begin{array}{c}84 \\
(39.81 \%)\end{array}$ & $\begin{array}{c}25 \\
(11.85 \%)\end{array}$ \\
\hline MRI/TRUS targeted biopsy + Systematic biopsy $(\mathrm{TG}+\mathrm{SB})$ & $\begin{array}{c}113 \\
(53.55 \%)\end{array}$ & $\begin{array}{c}85 \\
(40.28 \%)\end{array}$ & $\begin{array}{c}28 \\
(13.27 \%)\end{array}$ \\
\hline \multicolumn{4}{|l|}{ Repeated biopsy group } \\
\hline MRI/TRUS targeted biopsy (TG) & $\begin{array}{c}59 \\
(33.91 \%)\end{array}$ & $\begin{array}{c}47 \\
(27.01 \%)\end{array}$ & $\begin{array}{c}12 \\
(6.90 \%)\end{array}$ \\
\hline Systematic biopsy (SB) & $\begin{array}{c}68 \\
(39.08 \%)\end{array}$ & $\begin{array}{c}44 \\
(25.29 \%)\end{array}$ & $\begin{array}{c}24 \\
(13.79 \%)\end{array}$ \\
\hline MRI/TRUS targeted biopsy + Systematic biopsy $(\mathrm{TG}+\mathrm{SB})$ & $\begin{array}{c}83 \\
(47.70 \%)\end{array}$ & $\begin{array}{c}61 \\
(35.06 \%)\end{array}$ & $\begin{array}{c}23 \\
(13.22 \%)\end{array}$ \\
\hline
\end{tabular}

Clinically insignificant prostate cancer was defined as the presence of localized cancer with a Gleason score $6,<3$ positive biopsy cores, and $<50 \%$ prostate cancer in a biopsy core ${ }^{5}$. Primary outcomes were to confirm the superiority of $\mathrm{TG}$ or $\mathrm{TG}+\mathrm{SB}$ over standard $\mathrm{SB}$ in the $\mathrm{FB}$ and $\mathrm{RB}$ groups and to find inter-examiner differences in detection rates for MRI/TRUS fusion TG.

Four examiners from two departments were involved. The examiners were ranked from 1 to 4 based on their level of experience with TRUS guided biopsies. Examiner 1 had 18 years of experience with transrectal prostate biopsies (more than 1000 TRUS guided biopsies performed previously), Examiner 2 had 15 years of experience (more than 800 TRUS guided biopsies performed previously), Examiner 3 had 2 years of experience but was working under the direct supervision of Examiner 1 or 2, and Examiner 4 had 5 years of experience with transrectal biopsies (more than 250 TRUS guided biopsies performed previously). Patients were randomly assigned to the examiners based on a routine operating room schedule. Detection rates were calculated for each examiner and stratified according to PIRADS scores. In this sub-analysis, 23 patients were excluded due to the radiologist's inability to specify a PIRADS score for the lesions (absence of DCE sequence because of contraindications for application of contrast medium).
Table 3. $P$-values in the comparison of targeted and systematic biopsies.

\begin{tabular}{lcc}
\hline All cancers & SB vs. TG & SB vs. TG+SB \\
\hline First biopsy group & $P<0.001$ & n.s. \\
Repeated biopsy group & n.s. & n.s. \\
Clinically significant cancers & SB vs. TG & SB vs. TG+SB \\
First biopsy group & 0.041 & n.s. \\
Repeated biopsy group & n.s. & 0.047 \\
Insignificant cancers & SB vs. TG & SB vs. TG+SB \\
First biopsy group & 0.008 & n.s. \\
Repeated biopsy group & 0.035 & n.s. \\
\hline
\end{tabular}

To exclude any bias influencing the calculation of inter-examiner variability, the PSA values, free to total PSA index (f/t PSA), patient age, and prostate size of each examiner's group of patients were compared. No significant differences were found in age $(P=0.845)$, PSA $(P=0.472)$, or $\mathrm{f} / \mathrm{t}$ PSA $(P=0.496)$ between examiner subgroups in the FB group. Average prostate volume was significantly different among examiner groups, but it was not considered clinically significant $(52.19 \mathrm{~mL}, 47.16 \mathrm{~mL}$, $48.22 \mathrm{~mL}$, and $64.23 \mathrm{~mL}, P<0.001$ ) in the FB group. No significant differences in age $(P=0.339)$, PSA $(P=0.274)$, 
Table 4. Biopsy detection rates stratified according to examiners and PIRADS score.

\begin{tabular}{|c|c|c|c|c|c|c|c|c|}
\hline & \multirow[b]{2}{*}{$\begin{array}{c}\text { Number of } \\
\text { patients }\end{array}$} & \multirow[b]{2}{*}{$\begin{array}{c}\text { Number } \\
\text { of patients } \\
\text { PIRADS } \geq 3\end{array}$} & \multicolumn{2}{|c|}{ TG } & \multicolumn{2}{|c|}{ SB } & \multicolumn{2}{|c|}{$\mathrm{TG}+\mathrm{SB}$} \\
\hline & & & $\begin{array}{c}\text { Number of } \\
\text { patients with } \\
\text { cancer }\end{array}$ & $\begin{array}{l}\text { Detection } \\
\text { rate }\end{array}$ & $\begin{array}{c}\text { Number of } \\
\text { patients with } \\
\text { cancer }\end{array}$ & $\begin{array}{l}\text { Detection } \\
\text { rate }\end{array}$ & $\begin{array}{c}\text { Number of } \\
\text { patients with } \\
\text { cancer }\end{array}$ & $\begin{array}{l}\text { Detection } \\
\text { rate }\end{array}$ \\
\hline \multicolumn{9}{|c|}{ First biopsy group } \\
\hline Examiner 1 & 68 & 53 & 28 & $52.83 \%$ & 34 & $64.15 \%$ & 36 & $67.92 \%$ \\
\hline PIRADS 3 & & 15 & 3 & $20.00 \%$ & 4 & $26.67 \%$ & 5 & $33.33 \%$ \\
\hline PIRADS 4 & & 27 & 16 & $59.26 \%$ & 19 & $70.37 \%$ & 20 & $74.07 \%$ \\
\hline PIRADS 5 & & 11 & 9 & $81.82 \%$ & 11 & $100.00 \%$ & 11 & $100.00 \%$ \\
\hline Examiner 2 & 31 & 18 & 6 & $33.33 \%$ & 10 & $55.56 \%$ & 11 & $61.11 \%$ \\
\hline PIRADS 3 & & 10 & 3 & $30.00 \%$ & 5 & $50.00 \%$ & 5 & $50.00 \%$ \\
\hline PIRADS 4 & & 7 & 3 & $42.86 \%$ & 4 & $57.14 \%$ & 5 & $71.43 \%$ \\
\hline PIRADS 5 & & 1 & 0 & $0.00 \%$ & 1 & $100.00 \%$ & 1 & $100.00 \%$ \\
\hline Examiner 3 & 36 & 29 & 10 & $34.48 \%$ & 21 & $72.41 \%$ & 21 & $72.41 \%$ \\
\hline PIRADS 3 & & 14 & 4 & $28.57 \%$ & 11 & $78.57 \%$ & 11 & $78.57 \%$ \\
\hline PIRADS 4 & & 13 & 4 & $30.77 \%$ & 8 & $61.54 \%$ & 8 & $61.54 \%$ \\
\hline PIRADS 5 & & 2 & 2 & $100.00 \%$ & 2 & $100.00 \%$ & 2 & $100.00 \%$ \\
\hline Examiner 4 & 86 & 74 & 20 & $27.03 \%$ & 33 & $44.59 \%$ & 33 & $44.59 \%$ \\
\hline PIRADS 3 & & 37 & 5 & $13.51 \%$ & 11 & $29.73 \%$ & 10 & $27.03 \%$ \\
\hline PIRADS 4 & & 31 & 10 & $32.26 \%$ & 17 & $54.84 \%$ & 18 & $58.06 \%$ \\
\hline PIRADS 5 & & 6 & 5 & $83.33 \%$ & 5 & $83.33 \%$ & 5 & $83.33 \%$ \\
\hline$P$-value & & & & $P=0.029$ & & $P=0.037$ & & $P=0.017$ \\
\hline \multicolumn{9}{|c|}{ Repeated biopsy group } \\
\hline Examiner 1 & 68 & 62 & 26 & $41.94 \%$ & 23 & $37.10 \%$ & 31 & $50.00 \%$ \\
\hline PIRADS 3 & & 25 & 6 & $24.00 \%$ & 6 & $24.00 \%$ & 8 & $32.00 \%$ \\
\hline PIRADS 4 & & 30 & 13 & $43.33 \%$ & 12 & $40.00 \%$ & 16 & $53.33 \%$ \\
\hline PIRADS 5 & & 7 & 7 & $100.00 \%$ & 5 & $71.43 \%$ & 7 & $100.00 \%$ \\
\hline Examiner 3 & 15 & 12 & 2 & $16.67 \%$ & 4 & $33.33 \%$ & 5 & $41.67 \%$ \\
\hline PIRADS 3 & & 7 & 2 & $28.57 \%$ & 3 & $42.86 \%$ & 4 & $57.14 \%$ \\
\hline PIRADS 4 & & 4 & 0 & $0.00 \%$ & 1 & $25.00 \%$ & 1 & $25.00 \%$ \\
\hline PIRADS 5 & & 1 & 0 & $0.00 \%$ & 0 & $0.00 \%$ & 0 & $0.00 \%$ \\
\hline Examiner 4 & 91 & 78 & 25 & $32.05 \%$ & 32 & $41.03 \%$ & 37 & $47.44 \%$ \\
\hline PIRADS 3 & & 38 & 9 & $23.68 \%$ & 10 & $26.32 \%$ & 13 & $34.21 \%$ \\
\hline PIRADS 4 & & 31 & 10 & $32.26 \%$ & 13 & $41.94 \%$ & 15 & $48.39 \%$ \\
\hline \multirow[t]{2}{*}{ PIRADS 5} & & 9 & 6 & $66.67 \%$ & 9 & $100.00 \%$ & 9 & $100.00 \%$ \\
\hline & & & & n.s. & & n.s. & & n.s. \\
\hline
\end{tabular}

$\mathrm{f} / \mathrm{t}$ PSA $(P=0.457)$, prostate size $(P=0.172)$, and PSA density $(P=0.173)$ between examiner subgroups in the $\mathrm{RB}$ group.

\section{Study group characteristics}

The characteristics of the study groups are given in Table 1. Significant differences were found between the FB and RB groups for all variables (two-sample $t$ test, $P<0.001)$. Therefore, all analyses were performed separately for these two groups.

\section{Statistical analysis}

Statistical analyses were performed using the statistical software R 3.4.3. Continuous variables were reported as means and standard deviations, categorical variables as proportions (\%). Two-sample t test or ANOVA were used to compare baseline characteristics between the FB and RB groups and between examiners. The chi-squared test was used to test differences in the detection rate between $\mathrm{TG}, \mathrm{SB}$, and TG+SB biopsy and between examiners. All tests were performed at the $5 \%$ level of significance. 


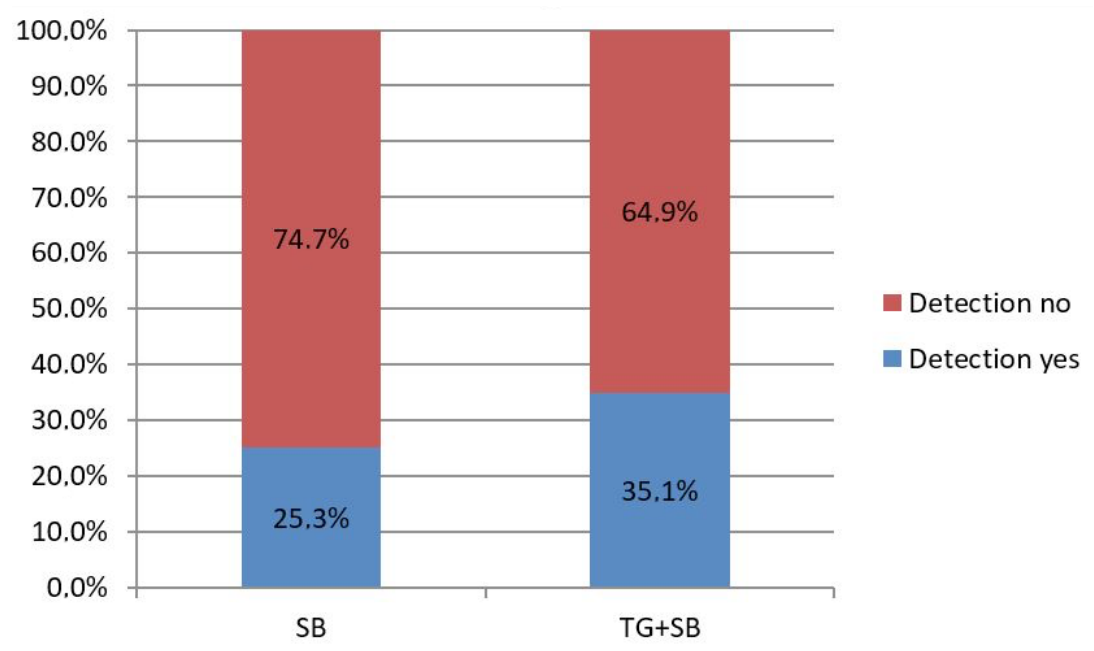

Fig. 1. Comparison of systematic biopsy (SB) against targeted and systematic biopsy $(\mathrm{TG}+\mathrm{SB})$ in the repeated biopsy group in the detection of clinically significant prostate cancer $(P=0.047)$.

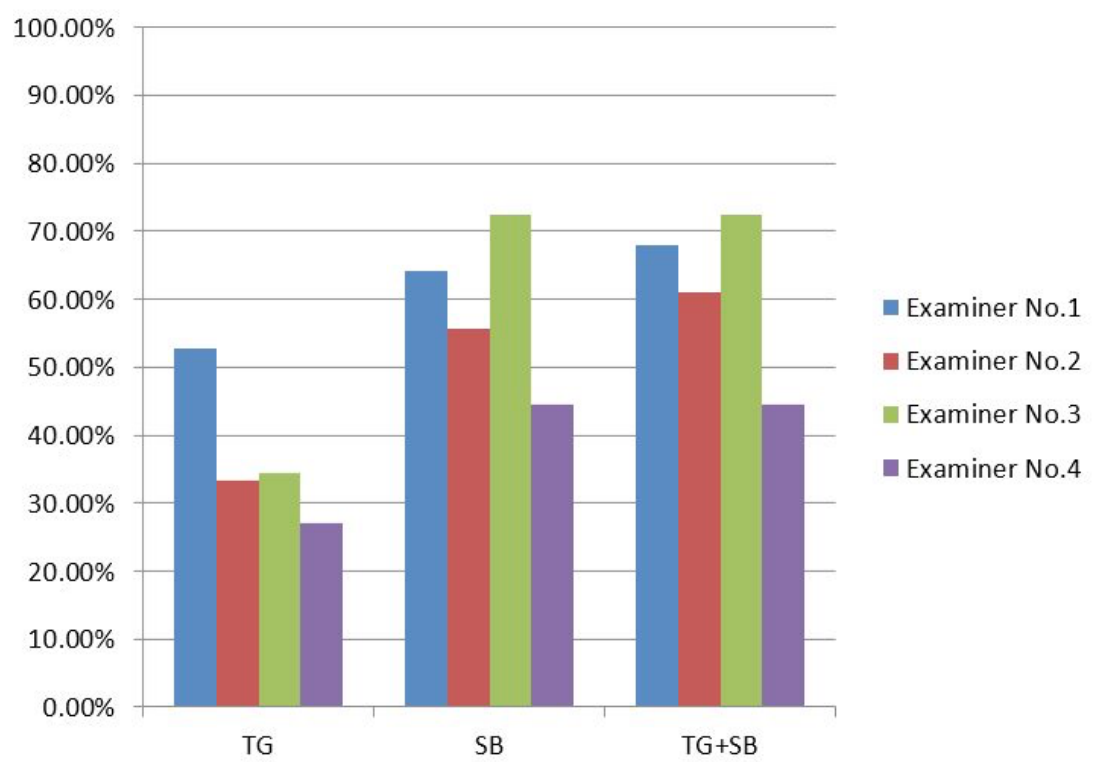

Fig. 2. Inter-individual variability of detection rates in the first biopsy group. Systematic biopsy (SB), targeted biopsy (TG)

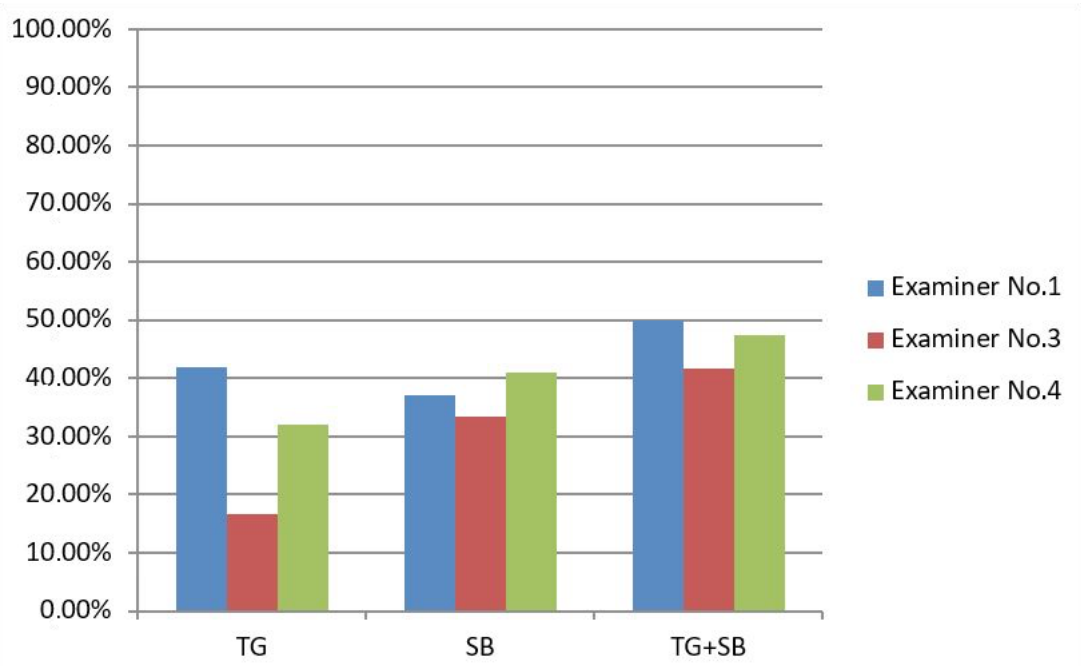

Fig. 3. Inter-individual variability of detection rates in the repeated biopsy group. Systematic biopsy (SB), targeted biopsy (TG). 


\section{RESULTS}

\section{Superiority of TG or TG+SB over standard SB}

Detection rates are presented in Table 2 . The $P$-values comparing TG and SB are in Table 3. A significant difference was found for $\mathrm{TG}+\mathrm{SB}$ vs. $\mathrm{SB}$ in the $\mathrm{RB}$ group for the detection of clinically significant prostate cancer (Fig. 1). SB had a significantly higher detection rate than TG in both subgroups (FB and RB) for the detection of clinically insignificant prostate cancer.

\section{Inter-examiner differences in detection rates}

The results of biopsies stratified by examiner are given in Table 4. Inter-individual variability in detection in the FB and RB groups is shown in Fig. 2 and 3. A significant difference was found among the four examiners in the FB group for $\mathrm{TG}, \mathrm{SB}$, and $\mathrm{TG}+\mathrm{SB}$. The detection rates of MRI/TRUS fusion TG reflect the extent of previous experience with TRUS guided prostate biopsy; the most experienced examiner had the best detection rates with TG.

\section{DISCUSSION}

Targeted MRI/TRUS fusion biopsy is a well-established method with proved efficacy. Siddiqui et al. showed that, among men undergoing biopsy for suspected prostate cancer, targeted MRI/ultrasound fusion biopsy is associated with increased detection of high-risk prostate cancer and decreased detection of low-risk prostate cancer compared to standard extended-sextant ultrasound-guided biopsy $^{6}$. In a meta-analysis, Schootes et al. revealed an improvement in the detection of clinically significant prostate cancer by MRI-targeted biopsy in men with previous negative biopsy compared to men with initial biopsy ${ }^{7}$.

In our group of patients, MRI/TRUS fusion TG significantly improved the detection rate only in the case of $\mathrm{RB}$. The best results were reached with a combination of SB and TG. Our data are consistent with other studies summarized in the systematic review by vanHove et al., who concluded that most studies have shown that the combination of both methods, systematic and targeted MRI/TRUS prostate fusion biopsy, is becoming the gold standard for prostate re-biopsy ${ }^{8}$.

Our study does not show a significant benefit in patients without previous biopsy. TRUS guided SB better detected clinically significant prostate cancer than MRI/ TRUS fusion TG in the FB group. On the other hand, systematic TRUS guided biopsy had significantly higher detection rates for clinically insignificant prostate cancer in both subgroups of patients in our study. This is one of the well-recognized disadvantages of systematic TRUS guided biopsy, which is performed randomly without any targeting in most cases ${ }^{9}$.

Furthermore, we showed significant differences in detection rates in the FB group among the four examiners performing TG and SB. Only three examiners performed biopsies in the RB group. There are clear differences in the detection rates for the TGs $(41 \%, 32 \%, 16 \%)$, but the results were not significant due to the small number of biopsies performed by some of the examiners. We analyzed the reasons for the different detection rates among examiners and found that the results were dependent on previous experience with TRUS guided biopsies. The most experienced examiner had the best results for TG, and less experienced examiners compensated for the detection rate in TG with higher detection rates in random SB. Examiner 3 was the least experienced but worked under the direct supervision of the most experienced examiners ( 1 or 2 ). His results were better in some cases than those of examiner 4, who had intermediate experienced. It seems crucial that SB follow TG, especially with less experienced examiners.

Although some studies have not shown significant benefits of software fusion versus cognitive fusion ${ }^{10}$, the benefit of software fusion biopsy is mainly seen in better targeting of small and anterior lesions ${ }^{9,10}$. In cognitive fusion biopsies, good results have been achieved in studies in which biopsy is performed by a radiologist with previous experience in TRUS guided biopsy ${ }^{11}$. Software fusion should lead to simplification of the targeting process and allow the spread of MRI/TRUS fusion targeted biopsy among more examiners.

The simplicity and good results of the system used in this study for MRI/TRUS fusion were also described in other studies ${ }^{12}$. However, it is obvious that this method is also dependent on the performance of examiners and their experience with previous TRUS guided biopsy, as well as mpMRI reading. According to our results, significant inter-examiner variability is present and dependent on previous experience with TRUS guided biopsies.

There are at least two trends to advance the use of MRI in clinical practice. The first trend is the use of mpMRI and TG in all subgroups of patients, including patients without prior biopsy ${ }^{13}$. The other trend is omitting SB after MRI-targeted biopsy, which could reduce the capture of insignificant carcinomas. ${ }^{14}$ In agreement with other studies, our results show that, prior to these steps, the results of mpMRI and TG should be checked carefully ${ }^{15}$.

A limitation of this study is the small number of patients, especially in the subgroup analysis. It is also essential to determine a learning curve for the whole process of MRI/TRUS fusion targeted prostate biopsy.

\section{CONCLUSION}

A significant improvement in prostate biopsy was shown in the RB group by adding MRI/TRUS fusion biopsy to SB. Clinically insignificant prostate cancer was detected better by SB than TG in both the FB and RB groups. Significant differences were found in detection rates among examiners performing MRI/TRUS fusion TG depending on their previous experience with TRUS guided biopsies.

Inter-individual variability in the performance of different examiners may blur the overall detection rates of MRI/TRUS fusion TG and SB. Therefore, it is necessary 
to focus on the results of individual examiners. Quality control is needed to ensure good results of TG. Results should be enhanced with proper training and the supervision of less experienced examiners.

Acknowledgements This work was supported by the Agency for Healthcare Research MZČR, project number 15-27047A.

Author contributions: MZ: conception and design of study, acquisition of data, analysis and interpretation of data, drafting of the manuscript; JS: acquisition of data, analysis and interpretation of data, drafting of the manuscript; IM: aacquisition of data, critical revision of the manuscript for important intellectual content; VA: acquisition of data, analysis and interpretation of data, critical revision of the manuscript for important intellectual content; MB: conception and design of study, critical revision of the manuscript for important intellectual content; RZ: conception and design of study, critical revision of the manuscript for important intellectual content.

Conflict of interest statement: None declared.

\section{REFERENCES}

1. Mottet N, Bellmunt J, Bolla M, Briers E, Cumberbatch MG, De Santis M, Fossati N, Gross T, Henry AM, Joniau S, Lam TB, Mason MD, Matveev VB, Moldovan PC, van den Bergh RCN, Van den Broeck T, van der Poel HG, van der Kwast TH, Rouviere O, Schoots IG, Wiegel T, Cornford P. EAU-ESTRO-SIOG Guidelines on Prostate Cancer. Part 1: Screening, Diagnosis, and Local Treatment with Curative Intent. Eur Urol 2017;71(4):618-29.

2. Porpiglia F, Manfredi M, Mele F, Cossu M, Bollito E, Veltri A, Cirillo S, Regge D, Faletti R, Passera R, Fiori C, De Luca S. Diagnostic pathway with multiparametric magnetic resonance imaging versus standard pathway: results from a randomized pro- spective study in biopsy-naive patients with suspected prostate cancer. Eur Urol 2017;72(2):282-8.

3. Quentin M, Arsov C, Rohlen S, Klasen J, Antoch G, Albers P, Blondin $D$. Inter-reader agreement of multi-parametric MR imaging for the detection of prostate cancer: evaluation of a scoring system. Rofo 2012;184(10):925-9.

4. Barentsz JO, Richenberg J, Clements R, Choyke P, Verma S, Villeirs G, Rouviere O, Logager V, Futterer JJ, European Society of Urogenital R. ESUR prostate MR guidelines 2012. Eur Radiol 2012;22(4):746-57.

5. Epstein Jl, Walsh PC, Carmichael M, Brendler CB. Pathologic and clinical findings to predict tumor extent of nonpalpable (stage T1C) prostate cancer. JAMA 1994;271(5):368-74.
6. Siddiqui MM, Rais-Bahrami S, Turkbey B, George AK, Rothwax J, Shakir N, Okoro C, Raskolnikov D, Parnes HL, Linehan WM, Merino MJ, Simon RM, Choyke PL, Wood BJ, Pinto PA. Comparison of MR/ ultrasound fusion-guided biopsy with ultrasound-guided biopsy for the diagnosis of prostate cancer. JAMA 2015;313(4):390-7.

7. Schoots IG, Roobol MJ, Nieboer D, Bangma CH, Steyerberg EW, Hunink MG. Magnetic resonance imaging-targeted biopsy may enhance the diagnostic accuracy of significant prostate cancer detection compared to standard transrectal ultrasound-guided biopsy: a systematic review and meta-analysis. Eur Urol 2015;68(3):438-50.

8. van Hove A, Savoie PH, Maurin C, Brunelle S, Gravis G, Salem N, Walz J. Comparison of image-guided targeted biopsies versus systematic randomized biopsies in the detection of prostate cancer: a systematic literature review of well-designed studies. World J Urol 2014;32(4):847-58.

9. Wegelin O, van Melick HHE, Hooft L, Bosch J, Reitsma HB, Barentsz JO, Somford DM. Comparing Three Different Techniques for Magnetic Resonance Imaging-targeted Prostate Biopsies: A Systematic Review of In-bore versus Magnetic Resonance Imaging-transrectal Ultrasound fusion versus Cognitive Registration. Is There a Preferred Technique? Eur Urol 2017;71(4):517-31.

10. Wysock JS, Rosenkrantz AB, Huang WC, Stifelman MD, Lepor H, Deng FM, Melamed J, Taneja SS. A prospective, blinded comparison of magnetic resonance (MR) imaging-ultrasound fusion and visual estimation in the performance of MR-targeted prostate biopsy: the PROFUS trial. Eur Urol 2014;66(2):343-51.

11. Puech P, Rouviere $O$, Renard-Penna R, Villers A, Devos P, Colombel M, Bitker MO, Leroy X, Mege-Lechevallier F, Comperat E, Ouzzane A, Lemaitre L. Prostate cancer diagnosis: multiparametric MR-targeted biopsy with cognitive and transrectal US-MR fusion guidance versus systematic biopsy--prospective multicenter study. Radiology 2013;268(2):461-9.

12. Jelidi A, Ohana M, Labani A, Alemann G, Lang H, Roy C. Prostate cancer diagnosis: Efficacy of a simple electromagnetic MRI-TRUS fusion method to target biopsies. Eur J Radiol 2017;86:127-34.

13. Ahmed HU, El-Shater Bosaily A, Brown LC, Gabe R, Kaplan R, Parmar MK, Collaco-Moraes Y, Ward K, Hindley RG, Freeman A, Kirkham AP, Oldroyd R, Parker C, Emberton M, group Ps. Diagnostic accuracy of multi-parametric MRI and TRUS biopsy in prostate cancer (PROMIS): a paired validating confirmatory study. Lancet 2017;389(10071):81522.

14. Baco E, Rud E, Eri LM, Moen G, Vlatkovic L, Svindland A, Eggesbo HB, Ukimura O. A Randomized Controlled Trial To Assess and Compare the Outcomes of Two-core Prostate Biopsy Guided by Fused Magnetic Resonance and Transrectal Ultrasound Images and Traditional 12-core Systematic Biopsy. Eur Urol 2016;69(1):149-56.

15. Cash H, Gunzel K, Maxeiner A, Stephan C, Fischer T, Durmus T, Miller K, Asbach P, Haas M, Kempkensteffen C. Prostate cancer detection on transrectal ultrasonography-guided random biopsy despite negative real-time magnetic resonance imaging/ultrasonography fusion-guided targeted biopsy: reasons for targeted biopsy failure. BJU Int 2016;118(1):35-43. 